\title{
FISCALISM AS SPENDING AND MONETARY INTEGRATION
}

\author{
MASUDUL ALAM CHOUDHURY \\ Institute of Islamic Banking and Finance \\ International Islamic University Malaysia \\ NOREHA HALID \\ Faculty of Economics and Management \\ Universiti Kebangsaan Malaysia \\ MOHAMMED SALEH AHMED \\ Department of Mathematical and Statistics \\ Sultan Qaboos University \\ MOHAMMAD SHAHADAT HOSSAIN \\ Chittagong University \\ Chittagong Bangladesh
}

\begin{abstract}
Macroeconomic policy coordination and the field of micro-foundation of the macroeconomic theory have been riddled with the contest of claimed efficacy between the Keynesian school and the monetarist school. Keynesianism upheld the predominance of fiscalism (spending) in economic stabilization on the one side. Friedman's monetarist theory vouched for the same on the other side. As a result of the monetary and fiscal contest between the two schools a convergence between them could not be attained. Such a divide is similar in economic science as it has been a fiasco thus far in the physical sciences between Quantum Mechanics explaining the small world phenomenon, and Relativity Physics explaining the large world phenomenon. The nonhomogenous views of a unique reality in economics, as in science, have defied the unification of theories and application for the greater objective of wellbeing in an embedded social economy, beyond sheer address of the stabilization question. Our paper strides out in the new direction of a socioscientific epistemological worldview of the unification of monetary and fiscal (spending) regimes in a consolidated theory of complementarities between them. The paper does this by breaking new grounds that are based on the model of organic unity of knowledge, which acts upon the simulation of well-
\end{abstract}


being with the method of circular causation. A review of the literature and introduction of formalism are undertaken to expound the theme of economic stabilization by means of complementing monetary and fiscal (spending) regimes in a unified theory, while addressing the simulation of well-being in a learning model of unity of knowledge. The emergent methodology presents the description of a system of inter-variables circular causation relations. An extensive review of the literature is undertaken. An empirical presentation and a case study establish the validity of the well-being model with circular causation.

Keywords: Monetary and spending regimes, epistemology and economics, economic stabilization, well-being.

\section{Background}

The complementary use of monetary and spending regimes although much desired for economic expansion, this phenomenon remains plagued with uncertainty, unpredictability, and subject to perturbations that adversely affect stable price and output relations. For instance, the income multiplier effect of both spending and monetary liberalization near to the full-employment point of output, despite that the full-employment point itself is evasive of attainment, pushes the economy into the inflationary domain. Along the Keynesian aggregate supply curve and the monetarist classical aggregate supply curve the neutrality of monetary and spending policies to output causes the inflationary pressure. Throughout this paper, fiscalism is equated with spending (aggregate demand stimulation) rather than with government spending only.

Yet complementarities between monetarism and spending as real sector spending regimes and policies ${ }^{1}$ are much desired in order to engender long-run stable and non-inflationary economic expansion. The attainment of such complementarities in the stable and sustainable forms also unleashes sustainable consequences of the monetary and spending (spending) regimes on other critical variables of the money and spending functions. Among such variables are employment and real income and entitlements, real profitability and financial stability. Price stability along with the growth of output in the complementary monetary and spending regimes therefore involves endogenous and knowledge-induced learning linkages between the variables underlying the monetary and spending functions in the absence of 
interest rates. Interest rates as impediments to spending for the benefit of bank saving are replaced by rates of profits, market turnover rates or profitability yields in the real economy.

The attainment of non-inflationary economic growth with complementary monetary and spending regimes thus results in money, spending (spending) and real economy complementary interrelations. Such interrelations form a system of what we will refer to as circular causation. We will also show that a systemic study of complementary interrelations in the circular causation system also simulates towards attaining the well-being objective of the embedded economy in the social order. In the end, the theme of monetary and spending complementarities invokes a broader perspective. This is that of simulating the complementary linkages in the circular causation system of interrelations between the critical variables of the money and spending functions. Within these are realized proper types of resource mobilizing financial instruments, and the wellbeing objective.

\section{Objectives}

This paper will undertake a literature review of the underlying issues and problems of the complementary nature of monetary and spending regimes on the theme of sustainability of long-run non-inflationary growth with the attainment of well-being in an embedded social economy. The paper will develop a new model of the unified (complementary) synergistic linkages between money, spending expansion and the real economy through the choice of proper financial instruments that enable such complementarities to sustain with interest rates being replaced by productive rates.

The literature review pointing to the problems of monetary and spending complementarities leads to the formulation of a moneyspending-financial-real economy model (referred to as the MFSREmodel) in a system of circular causation between these sectors with endogenous technology and growth. The result shows the attainment of well-being by way of non-inflationary economic growth and its stabilizing, predictable, and long-term sustainable effects in the embedded social economy.

The paper is in the following parts: Part 1 discusses selected review of the literature on the problems of instability, unpredictability and perturbations caused by the traditional approaches to the study 
of monetary and spending regimes. The alternative perspective of a theory complementing monetary and spending regimes in a socially-embedded stable and sustainable economy is pointed out in the literature review. Such a social economy with complementary monetary and spending (spending) functions and the critical socioeconomic variables in these functions have a distinctive epistemological background of its own. Part 2 formalizes the alternative model of money, spending, financial and real economy (MFSRE) having its distinctive epistemological and formal analytics. The MFSRE model (Mufeedh Choudhury, 2009) takes the form of simulation of a well-being objective criterion in the complementary variables representing $\mathrm{M}, \mathrm{F}, \mathrm{S}, \mathrm{RE}$ sectors in a system of circular causation relations between the variables and the sectors. Part 3 analyses the theoretical and policy ramifications of the MFSRE-model in the light of a new theory of monetary and spending complementarities with technologically induced non-inflationary economic expansion. In this section the endogenous theory of economic growth and technological change invoking money and spending complementarities in the MFSRE-model is developed. Part 4 deals with a prescriptive direction for the MFSRE-model in the light of the microeconomic foundation of the macroeconomic theory underlying the model. Part 5 examines, though in a rudimentary way, the applicability of the MFSRE-model with Malaysian macroeconomic data.

\section{Literature Review}

In the history of economic thought (Blaug, 1993) monetary policy and spending policy mechanisms have remained opposed to each other on the issue of stable, sustainable, non-inflationary economic growth. Blaug (1993, p. 29) has pointed out this opposing consequences of the two approaches on non-inflationary economic expansion in his follow words: "The great debate between Keynesian and monetarists over the respective potency of spending and monetary policy has divided the economic profession, accumulating what is by now a simply enormous literature." But among the most distinctive cleavages that Blaug points out between monetarism and Keynesianism as the spending domain is the important role of knowledge that becomes the causal element of economic change. Knowledge is treated as being more than simply the determination of the signs of coefficients of parameters in economic models. 
This determining factor of knowledge that we will explain comprehends the epistemology and the ways arising from it in endogenously generating adjustments towards stability, though not steady-state equilibrium in the economy. The economy is now understood as a circular causation system of inter-relations. The theme of causality that underlies the inherent system of interrelations that encompass an integrated economy is strongly pointed out by Blaug (1993, p. 221): "Monetarism never succeeded in clarifying the causal mechanism that produced its empirical results, sometimes even denying that these results required interpretation in the light of a supporting causal theory, and it failed to refute any but a crude travesty of the Keynesian theory it opposed. Keynesianism on the other hand, proved to be capable of absorbing monetarist ideas in a more sophisticated brand of macroeconomics that appears to be emerging from the fifteen-year-old melee."

We point out the distinction of oppositeness and substance on the issue of causality related with the knowledge concept in the economic system in the footnote in a cursory way. ${ }^{2}$ The issue is of a vastly elaborate and rigorous nature (Von Bartalanffy, 1974; Skyttner, 2005; Maturana \& Varela, 1987). We will examine the substance of the formalism in this paper. The end result is that the randomness, perturbations, volatility and uncertainty caused by the indeterminateness of the combination between monetary and spending dynamics (policies and mechanism) do not establish causality and complementarities that attain economic stabilization. There remain permanently inflationary pressures caused by the plethora of short-term rates of interest that plague all the variables.

From the above-mentioned nature of the oppositeness of approaches between monetarism (Friedman) and Keynesianism (spending) there arises the problem of permanent instability in economic growth. This enigma is caused by the inconsistency relating price level, output and employment in respect of the expansion of the economic system by means of monetary and spending policies together or by piecemeal applications of one without the other. Instead, it is necessary to understand the theoretical and policy-institutional paradigm that can combine the two approaches together to generate the possibility of expansionary aggregate supply and aggregate demand curves without inflationary pressure. This kind of a sustainable economic growth involves a gamut of other consequences, such as employment and technological change on the economic side, and development issues such as participation, empowerment and poverty alleviation 
and thus social justice and social balance on the ethical front. The complementary question between monetary and spending approaches to economic expansion in a regime of price stability also establishes complementarities between the gamut of economic and social variables. The interrelations in such a complementary concept share fully the principle of circular causation that was invoked by Myrdal (1958).

On the same point, Toner (1999a, p. 124) writes importantly to bring out the distinction between mainstream economic theory, principally neoclassical economics, and the theory of circular causation that endogenously integrates economic and non-economic elements of a comprehensive understanding of economic theory for total well-being: "The notion of complementarity in production and consumption is central to CC (circular causation in the process of cumulative causation) theory. For Kaldor, given his concern with growth and dynamics as opposed to the allocation of fixed resources, complementarity in production and consumption is far more pervasive and significant than the neoclassical principle of substitution." The same kind of strong circular causation between economic and noneconomic complementarities is vouched by Kaldor (1975).

The interference of knowledge dynamics in terms of information flow taken in its wider sense of technological change of the participative nature in the economic system with a vast span of interactions between variables representing socioeconomic and policy goals and sectors is considered by Lucas (1975) in his theory of rational expectations. Yet the debate against the existence of a steady-state equilibrium in knowledge-induced systems of interrelations between diverse variables is not invoked in Lucas' model (Minford \& Peel, 1983). Instead, the monetary model of rational expectations is based on the assumption of adaptive dynamics in information flow. ${ }^{3}$ This kind of approach to the solution of the monetary model in rational expectation changes the monetary dynamics into a steady-state one with equilibrium once again replacing the endogenous dynamics of evolutionary equilibriums (Shakun, 1988).

Thus the paradigm of evolutionary equilibrium as the obverse side of the picture of perturbations by interaction and evolutionary knowledge-induced change has prevailed always. Consequently, in the case of the monetary and spending debate the goal of fullemployment and the nature of the analysis centered in aggregate demand, aggregate supply, IS and LM curves have continued on. 
Thereby, the possibility of endogenous effects has remained foreign in the development of a robust model of monetary and spending complementarities with sustained stabilization. On the other hand, endogenous causation is caused by factors such as the following ones: knowledge-induction, perturbations, technological change, and a negation of the relationship between money, spending, output and interest rate in the IS-LM analysis. In the extended quantity theory equation of exchange (Friedman, 1989; 1960) the replacement of the diverse interest rate variables for the attainment of sustainable non-inflationary economic expansion gives rise to an altogether new perspective in the monetary and spending theory. Now a new category of thought and its formalism arises.

Mishkin (2007a) writes importantly on this issue. But his theory has a weak pointer to the above-mentioned problem caused by the nonconformity between monetary and spending dynamics. Only timedynamics, as opposed to knowledge-dynamics over time-recording is maintained. Yet it is true that the policy futures for the activities of central bank results in the breeding of a knowledge background for the reform of the monetary transmission mechanism.

The result ensuing from Mishkin's monetary policy strategy in stabilizing prices and sustaining growth without inflation is as follows: In his chapter on the role of the Central Bank's on the stabilization issue, Mishkin emphasizes the independence of the Central Bank role in the management of the key goals that we are concerned with in this paper. These are, price stability ought to be maintained along with output stability. Stability means holding inflation rate low while expanding the output. Monetary and spending policies ought to be aligned. The short-run goal of employment-price level tradeoffs to build upon long-term employment and a stability goal are not recommended. The central bank should have independence in setting its monetary goals and development of financial instruments.

The instability of the financial sector is the most problematic one. It ought to be given priority. The principal priority for central banks to follow is as Mishkin writes (op cit, p. 41): "Price stability should be the overriding, long-run goal of monetary policy". In our paper we emphasize that monetary policy should not be benign of spending policy in price and output stability with endogenous learning and technological change. Consequently, economic stabilization with complementary monetary and spending policies by a change in formalism away from monetarism (Friedman, 1960) and 
Keynesianism (spending) is needed. And why is this simultaneous policy application needed? That is because monetary policy focuses on private and market-oriented developments, such as the stock market and from thereon, the private savers across the board. On the other hand, government management of spending is necessary for serving investment and social objectives away from too much reliance on the market performance. Indeed, such was Keynes' original motivation when he was driven by implicating G.E. Moore's ethical views in economic stabilization with government expenditure effects expressed in the aggregate demand, aggregate supply, and the IS-LM policy-induction method for attaining stabilization.

Mishkin (2007b, pp. 59-73) furthermore points out an issue that is of interest for this paper. That is the topic of studying the combined effect of monetary (M) and spending regimes and policies (f) on asset prices $(\mathrm{P})$. Here we proxy spending (spending) effect by investment (I) and the growth of real assets that can be read off by the net worth of firms (NW) with the cost of capital (c) and the rate of interest (r) both declining. Such a chain relation between monetary and spending regimes affecting productive increase in prices in the presence of declining interest rates and cost of capital, which finally affect output $\mathrm{Y}$, is marked out as follows: $\mathrm{M} \uparrow \Rightarrow \mathrm{c} \downarrow \Rightarrow \mathrm{r} \downarrow \Rightarrow \mathrm{P} \uparrow \Rightarrow \mathrm{I} \uparrow \Rightarrow \mathrm{NW} \uparrow \Rightarrow \mathrm{Y} \uparrow$.

This relationship has an important bearing on our formulation of the MFSRE-model. That is a quantity of money $\mathrm{M}$ is combined with spending such as I and valuation of economic performance in terms of NW and Y; all these inter-relating through the route of lowering ' $\mathrm{C}$ ' and ' $r$ '. P increases is via the productivity effects of I and NW on Y. In the MFSRE-model of money, spending policy, financial instruments and the real economy we will show how such a model establishes linkages between these sectors via the phasing out of interest rate and cost of capital, while price stability in an expanding economy is reflected in the growth rate of $\mathrm{Y}$ remaining higher than the rate of change of $\mathrm{P}$ and at least equal to the rate of increase in the quantity of money.

\section{Other References on Money-spending Endogenous Relations}

We commence this section by definitions of some critical terms and concepts that we use in this paper to study the theme of complementarities between monetary and spending mechanisms for maintaining price stability with sustained economic expansion. 
The positive interrelations between the variables of the monetary and spending domains when studied by circular causation between them, which is by feedback, are termed as being endogenous between them. Among such variables are those pointed out in footnote 1 .

Because the presence of ' $r$ ' causes perturbations in the other variables, including the price level, ' $\mathrm{r}$ ' must be replaced by a variable that causes at least short-term predictability and stabilization. One such candidate is the profit-sharing rate denoted by ' $\rho$ '. By its relations with productivity and social selection of the kinds of goods in production along with risk-diversification, and thereby technological change, the derivatives $\partial \mathrm{y} / \partial \mathrm{r}>0$ with $\mathrm{dr} / \mathrm{dt}>0 ; \partial \mathrm{y} / \partial \mathrm{M}>0 ; \mathrm{dM} / \mathrm{dt}>0$ together; and $\partial \mathrm{y} / \partial \mathrm{f}>0$ and $\mathrm{df} / \mathrm{dt}>0$ simultaneously. Consequently, predictability and price stabilization are established along the path of economic expansion when technological change works endogenously in the money-spending interrelations.

However, since knowledge-induction over time marks the learning nature of the circular causation relations between the variables, a special form of dynamics based on evolutionary epistemology of the interacting variables to form and explain complementarities between them defines the learning domain of complementarities gained by interaction in the light of evolutionary epistemology of the system of inter-relations.

A system is defined here by the circular causation relations that evaluate the degree of complementarities or simulated reconstruction towards complementarities between the endogenously related variables. The vector now is $\{\mathrm{y}, \mathrm{M}, \mathrm{f}, \mathrm{P}, \rho\}$, which is now induced by the knowledge-flow arising from the epistemological roots. The Austrian School is highly acclaimed to take such an approach (von Mises, 1976). Out of the endogenous relations between money, spending and all the socioeconomic variables that best occurs in the free-market venue, Yeager (1997) referred to endogenous money in the relational sense of interaction and evolution occurring by a laissez faire concept of money.

The degree of complementarities between the variables reflects the premise of unity of knowledge. This in turn conveys the epistemological meaning of well-being. In the money-spending complementary relations such well-being is formulated in terms of the degree of pricestability and economic growth attained with technological advance that enhances the knowledge-flow. But technology while being a career is not the totality of epistemic knowledge. 
By denoting the knowledge-flows in the epistemological sense we obtain the entire knowledge-induced vector. This is now denoted by $\{y, M, f, P, \rho\}[\theta]$, meaning that each of the bracketed variables is induced by the epistemology of a complementary or participative meaning of well-being. Such a well-being criterion in its measurable form indicating the degree of complementarities that exist or can be normatively constructed, is denoted by $\theta=F(y, M, f, P, \rho)$. This criterion is simulated in the sense of the learning process by means of circular causation between the variables of the vector. We denote any of all such relations as $\mathrm{x}(\theta)=\mathrm{F}_{\mathrm{i}}(\mathrm{z} / \mathrm{x})[\theta]$. ' $\mathrm{i}$ ' denotes the specific of the $\mathrm{x}$-variables in the vector $(y, M, f, P, \rho)$. ' $z / x^{\prime}$ denotes the vector without the $x$-variable. All variables are epistemologically driven by the normative outlook of unity of knowledge in the complementary system.

In the especial case of the complementarities between money and spending variables the equations are as follows: $\mathrm{M}=\mathrm{F}_{\mathrm{m}}(\mathrm{y}, \mathrm{f}, \mathrm{P}, \rho)[\theta]$; $\mathrm{f}=\mathrm{F}_{\mathrm{f}}(\mathrm{y}, \mathrm{M}, \mathrm{P}, \rho)[\theta]$. The consequential price and output variables to determine the degree of stability with economic growth in the system are as follows: $\mathrm{P}=\mathrm{F}_{\mathrm{P}}(\mathrm{y}, \mathrm{M}, \mathrm{f}, \rho) ; \mathrm{y}=\mathrm{F}_{\mathrm{y}}(\mathrm{M}, \mathrm{f}, \mathrm{P}, \rho)$. The productivity relation, synonymously the technology relationship is given by, $\rho=F_{\rho}(y, M, f, P)$. Thus, all the equations are firstly estimated. Thereafter the estimated relations are normatively simulated by affecting changes in the estimated coefficients so as to generate overall complementarities, especially between $\mathrm{M}$ and $\mathrm{f}$, as suggested by the epistemological meaning of $\theta$.

\section{Formulating the Money, Finance, Spending and Real Economy (MFSRE) Model}

By taking stock of the above-mentioned arguments we can formulate the complete MFSRE model as follows:

$$
\text { Simulate well-being function, } \mathrm{W}=\mathrm{W}(\mathrm{y}, \mathrm{M}, \mathrm{f}, \mathrm{P}, \mathrm{E}, \rho)
$$

Subject to the circular causation relations in respect of estimation followed by the simulated levels of complementary relations between $\{y, M, f, P, E, \rho\}$. The variable $E$ denotes the level of employment, which can be alternatively expressed as employment rate:

$y=F_{y}(M, f, P, E, r)$ in linear or non-linear form of the functional form of $\mathrm{F}_{\mathrm{y}}$;

$\mathrm{M}=\mathrm{F}_{\mathrm{M}}(\mathrm{y}, \mathrm{f}, \mathrm{P}, \mathrm{E}, \rho)$ in linear or non-linear form of the functional form of $\mathrm{F}_{\mathrm{M}^{\prime}}$; 
$f=F_{f}(y, M, P, E, r)$ in linear or non-linear form of the functional form of $\mathrm{F}_{\mathrm{f}^{\prime}}$

$\mathrm{P}=\mathrm{F}_{\mathrm{p}}(\mathrm{y}, \mathrm{M}, \mathrm{f}, \mathrm{E}, \mathrm{r})$ in linear or non-linear form of the functional form of $\mathrm{F}_{\mathrm{p}}$;

$\mathrm{E}=\mathrm{F}_{\mathrm{E}}(\mathrm{y}, \mathrm{M}, \mathrm{f}, \mathrm{P}, \mathrm{r})$ in linear or non-linear form of the functional form of $\mathrm{F}_{\mathrm{E}}$;

$\mathrm{P}=\mathrm{F}_{\mathrm{p}}(\mathrm{y}, \mathrm{M}, \mathrm{f}, \mathrm{P}, \mathrm{E})$ in lnear or non-linear form of the functional form of $\mathrm{F}_{\mathrm{p}}$;

$\theta=\mathrm{o}(\mathrm{y}, \mathrm{M}, \mathrm{f}, \mathrm{P}, \mathrm{E}, \mathrm{r})$ in linear or non-linear form of the functional form of $F_{0}$.

The circular causation relations (2)-(8) imply either the existence of or the normative reconstructive possibility for inter-variable complementarities. Such estimations are followed by simulation. The simulated, and thereby learning coefficients in the epistemological light of unity of knowledge, hence the degrees of complementarities possible, explain the endogenous nature of the variables in circular causation inter-relations.

How do we explain the passage from 'estimation' to 'simulation' in order to interpret the prevailing positivistic state followed by the normative reconstructive possibilities in terms of the MFSRE-model to explain complementarities between the sectors by the circular causation method? Within these sectors represented by the variables are embedded the measurement of well-being and the moneyspending complementarities to establish price stabilization and economic expansion.

In the MFSRE-model the normative picture is that, the quantity of money is brought to connect with real economic activities via suitable productivity-based financial instruments. The spending activity takes place in the real economy to support productivity-related activities with technical change. In the absence of interest rates and cost of capital, the mobilization of money into real economy activities, as is the case of spending in productive activities such as investment, causes increase in $(\mathrm{y}, \mathrm{f}, \mathrm{E})$. Thereby, $\rho$ increases as long as technological advance and endogenous relations between the variables realize increasing returns to scale (Toner, 1999b).

The above kinds of effects mean that as the technology-inducing variable $\rho$ increases, increasing returns and the interconnection between monetary and spending (spending) regimes cause prices 
to increase at rates lower than the rate of real output. This is the meaning of stable prices. Consequently, $\left[(1 / \mathrm{P})^{*}(\mathrm{dP} / \mathrm{dt})\right] /\left[(1 / \mathrm{y})^{*}(\mathrm{dy} /\right.$ $\mathrm{dt})]=\varepsilon_{\mathrm{p}, \mathrm{y}}$ decreases with an increase in $\mathrm{y}$. That is, the growth rate of $\mathrm{y}$ increases more than the rate of inflation. This is equivalent to having the elasticity of $p$ in respect of $y$ to decrease with the increasing effect of technological change as represented by $\rho$-effect.

We bring out these consequences in Figure 1. The effect of technological advancement on monetary regime is indicated by the shifting LMcurve. The IS-curve presents the spending regime. Now decreasing positive values of $\varepsilon_{p, y}$ causes points like ' $a$ ' to shift to ' $b$ ' and ' $c$ ' into the increasing levels of $\mathrm{y}$, for $\left[(1 / \mathrm{P})^{*}(\mathrm{dP} / \mathrm{dt})\right] /\left[(1 / \mathrm{y})^{*}(\mathrm{dy} / \mathrm{dt})\right]=\varepsilon_{\mathrm{p}, \mathrm{y}}$ declines causing the relative slopes $(\mathrm{dP} / \mathrm{dt}) /(\mathrm{dy} / \mathrm{dt})$ to decrease increasingly as $y$ increases at an increasing rate above the rate of change in price level with technological induction. The result in the end is price stability. This increases the real output and sustains technological change.

Besides, technological change is sustained endogenously by a learning process, as interactions proceed between all variables. Equation (7) conveys the theoretical implication that the positive coefficients of other variables as shown will have a net positive effect on technological advance. Likewise, positive coefficients of ' $\rho$ ' in the equations (2)-(6) will have positive effects on the other predictors.

The expectation on the signs of the estimated coefficients is though not guaranteed. The positivistic nature of data could prove otherwise. For instance, it is possible that interest rates and the cost of capital do not decline; yet the price level remains stable by the action of higher interest rate policy. It is also possible in this case for the financial sector to grow in opposition to the real sector. Consequently, output would grow under the force of financial growth.

Yet at the end, the well-being will be adversely affected; for endogenous technological change would fail to exist to complement the increasing levels of employment and price stability. The intent of MFSRE-model will be lost by the loss of complementarities between the sectors.

Most importantly, the real economic sector and the financial sector will fail to complement as resources move away from the real sector into the financial sector in the form of bank-savings. Bank-savings become withdrawals from the real economy, and hence impede productivity gains. This is shown both by the Keynesian comparative statics and the intertemporal case. The role of knowledge dynamics in the 
generalized system of complementarities that need to be formed by endogenous circular causation relations as a total unification process between well-being-inducing possibilities becomes non-existent.

The positivistic results conveyed by 'estimation' of the system of circular causation (2)-(8) are therefore, simulated by correcting the unwanted signs of the coefficients. An example here will suffice to convey the approach to the normative alternative. Other cases can be explained and applied accordingly by their respective normative correctives.

Take the case of the log-linear form:

$$
\begin{aligned}
& \log \mathrm{M}=\mathrm{A}+\mathrm{a} \cdot \log \mathrm{y}+\mathrm{b} \cdot \log \mathrm{f}+\mathrm{c} \cdot \log \mathrm{P}+\mathrm{d} \cdot \log \mathrm{E}+\mathrm{e} \cdot \log \rho \\
& \varepsilon_{\mathrm{M}, \mathrm{f}}=\mathrm{b} \\
& =(\mathrm{f} / \mathrm{M})^{*}(\mathrm{dM} / \mathrm{df})=\text { percentage change in } \mathrm{M} / \text { percentage } \\
& \text { change in } \mathrm{f} .
\end{aligned}
$$

A negative value or a small positive value of $\varepsilon_{\mathrm{M}, \mathrm{f}}$ that is statistically significant will imply a contractionary spending regime in the face of an expansionary monetary regime. By the usual use of the Keynesian comparative static analysis this situation can imply any of the following: crowding-out effect on real output y; or a drawdown of y. The way to arrest the drawdown of $\mathrm{y}$ is to keep ' $\mathrm{f}$ ' (IS curve) as close as possible to M (LM curve). This means better complementarities between the monetary and spending (spending) regimes. Such is the normative case as to how closely the spending expansion should be to complement with the expansionary monetary regime.

Besides the above-mentioned normative correction to attain complementary monetary and spending policy relationship, which is explained in reference to the IS-LM curves, the normative correction will also replace ' $r$ ' by ' $\rho$ ' reference on the vertical axis. The negative relationship between ' $r$ ' and ' $y$ ' yields the elasticity coefficients, $\varepsilon_{\rho, f}$ and $\varepsilon_{\rho, \mathrm{M}}$. The shapes of the $(\mathrm{P}, \mathrm{M}),(\mathrm{P}, \mathrm{F})$ are quite different from those of the LM-curve in $(\mathrm{r}, \mathrm{M})$, and the IS-curve in $(\mathrm{r}, \mathrm{F})$ taken together with increasing $\rho$ (technology effect). In the $\rho$ (technology)-induced case the $(\mathrm{P}, \mathrm{M})$ and $(\mathrm{P}, \mathrm{F})$ curves are overlapping positively sloped at a stable $P$ value with increasing $\rho$ effect. In other words, the classical shortrun perfectly elastic aggregate supply curve is indefinitely enhanced to overlap with the Keynesian elastic form of the aggregate supply 
curve. Monetarism and spending regime are thus made to converge to a common interactive goal of price stability and expansion of real output.

The further result that arises from these kinds of inter-variable relations is that there is no constrained notion of full-employment level of output in the case of technologically-induced consequences on price and output stability and sustainability caused by complementarities between monetary and spending regimes, as otherwise is the case in the IS-LM analysis of full-employment.

Normatively by simulation the coefficient signs between the variables can be expected by the following relations:

$$
\left.\mathrm{M} \uparrow \Rightarrow \mathrm{f} \uparrow \Rightarrow \mathrm{r} \downarrow \Rightarrow \mathrm{c} \downarrow \Rightarrow \mathrm{P}^{\wedge} \rightarrow 0\right) \Rightarrow \mathrm{y} \uparrow \Rightarrow \mathrm{E} \uparrow \Rightarrow \mathrm{p} \uparrow,
$$

$\mathrm{P}^{\wedge}$ denotes rate of change in price level; $\left(\mathrm{P}^{\wedge} \rightarrow 0\right)$ denotes convergence to price stability.

The system of feedback inter-relations (11) is everywhere circular, and thereby, there are pervasive inter-variable complementarities. This phenomenon is also shown by the equations (2)-(8). The circular causation chain (11) is similar to that given by Mishkin, shown above, to explain the MFSRE-type relationship in respect of real asset valuation. In our case we note the complementarities between the monetary regime $(\mathrm{M}, \mathrm{r}, \mathrm{c})$, spending (spending) regime $(\mathrm{f})$, and the real economy $\left(\mathrm{y}, \mathrm{E}, \mathrm{P}^{\wedge}, \rho\right)$.

The message inherent in the circular causation relations (1)-(8) also points to the role of knowledge in this system of endogenously complementary relations. Knowledge in this case means the unification (shown by positive signs of coefficients) between the appropriate variables. This is necessarily a normative phenomenon, but can also be a positivistic one if the expected correct signs of the coefficients exist.

Figure 1 summarizes much of the theoretical results mentioned above in the contrasting paradigms of circular causation in terms of the stability relations between the monetary regime, the spending regime, price stability, and economic expansion with technological change and growth of productivity. On the side of the theory of complementary endogenous relations between the various sectors of the MFSRE-model, Figure 1 points out the following dynamics: The $\mathrm{P}$ 
level replaces the interest rate because of the monotonic relationship between inflation targeting and the old Keynesian and monetarist comparative statics (Benanke \& Mishkin, 2007). That is to say, a certain price target is set towards which inflation is to gravitate and spell out the monetary policies needed to maintain the inflation target.

In the case of the complementary-dynamics of circular causation of endogenous interrelations between the selected variables as in the system (1)-(8) shown above, the price variable is not set ad hoc by the Central Bank independence of functions and policy targets. Rather, the normative direction by simulation, if the positivistic results do not show by estimation, ought to engineer the inter-variables circular causation relations in such a way as to result endogenously in price stability around a point, but not exactly at a given point. There is the matter of imperfect knowledge, adaptive knowledge as in rational expectations, and incompleteness of knowledge as organic inter-variables linkages in the system of circular causation learn to complement. The appearance of $\mathrm{P}\left(\right.$ rate $\left.\mathrm{P}^{\wedge}\right)$ on the vertical axis in place of ' $r$ ' is therefore acceptable.

In the diagram on complementarities the shifting of the spending curve (IS) and the monetary curve (LM) is enhanced by the effectiveness of technology ( $\rho$-effect). As this takes effect, the slopes of the IS curve decrease and the decreasing angles, $\alpha, \beta, \delta$ etc. show the convergence between the IS and LM curves. The price-stability is thereby attained across increasing real output levels with the technology effect causing increasing returns to scale. The convergent price-output path to the approximated form of stability in this case is shown.

The lower diagram of Figure 1 is of the monetarist-spending complementary case. It shows that after a non-inflationary expansion of the economy along the Keynesian under employment levels of output, income multipliers work towards slowing down, but not eliminating the income multiplier effect as the IS curves narrows down towards the LM curve near to the full-employment level of output. At this level the temporary price stability gives way to inflationary regime with growing neutrality of monetarist and spending regimes on the growth of real output. The price-output path is thus shown.

Clearly then, the two diagrams can become identical with the flattening of the IS and LM curves under the impact of technological advancement but of the endogenous type. In such a case it is possible to introduce the effectiveness of circular causation with the 
IJMS 20 (1), 1-39 (2013)

technological effect on monetarist and spending relations causing complementarities, and thereby, establishing and sustaining pricestability over the long run.

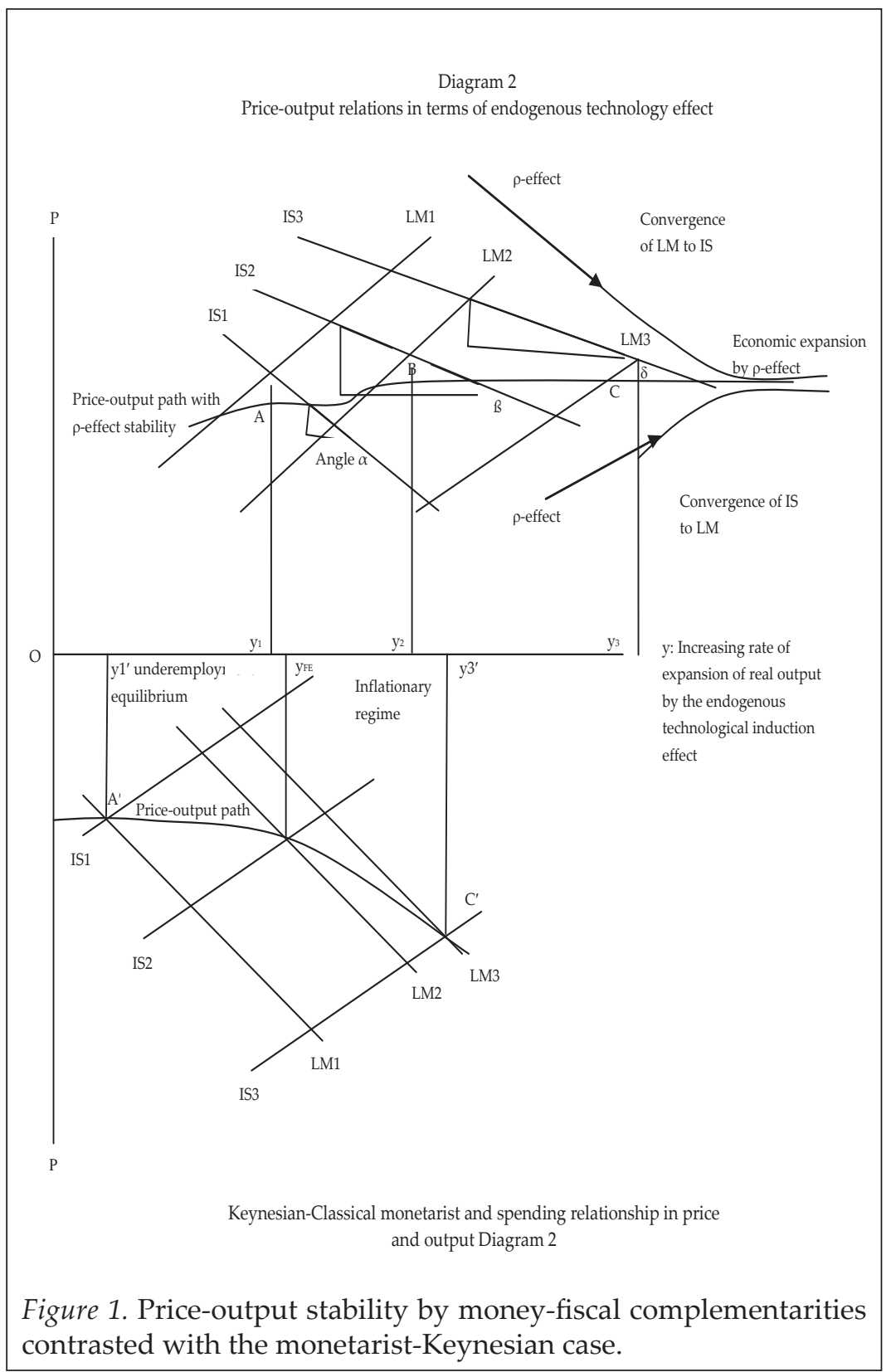




\section{The Effect of Endogenous Growth on Technological Advancement and Price-Output Stability Caused by Monetarist and Spending Complementarities}

It is noted from our formalism in this paper thus far that technological advance plays the critical role in the expansion of output along with price stability. In this way, all the critical variables are made to function in complementary ways with positive coefficients. Such signs are either determined by estimation (prevalent economic state) or by simulation (economic state as it ought to be). We have examined the circular causation interrelations between money and spending relationship, employment and investment. Other critical variables related to economic expansion and attainment of well-being can be tried out and studied in similar ways.

The expansion of technology is like the expansion of knowledge and information in the system of circular causation relations expressed by equations (1)-(8). The appearance of systemic knowledge as interaction leading to simulated complementarities and followed by evolutionary expansion of similar complementary relations is an epistemological issue on the unity of systemic knowledge. The emergence of such a learning system of evolutionary interrelations between the critical variables invokes the study of endogenous growth and development models. Such models take up specific characteristics of the learning equilibrium along epistemological lines.

Myrdal, who we have referred to earlier, Schumpeter (see Cantner et al., 2009), the Austrian School of Economics (Kirzner, 1997), the moral economy by Boulding (1971), and recently the new (endogenous) growth theory of Romer (1986) have left a legacy in the development of evolutionary socioeconomic growth and development. This paper follows along the same directions. There is a difference in the methodology though. Our objective criterion is not growth, development, economic expansion, wealth maximization, pricestabilization and the like per se. This paper treats all such goals to be instruments to attain the principal objective criterion of simulating well-being. The well-being criterion is defined as a measure of the degree to which complementarities exist or are attained by simulation under normative perspectives of ethical and policy futures.

Therefore, while Myrdal (1957) wrote on circular causation with cumulative causation in respect of the problems of the destitution of the Blacks in the United States, he multiplied such socially 
disruptive causations in his disequilibrium model. Boulding's perspectives of ecological futures in his model of social causation did not treat morality and ethics as endogenous forces of moralsocial reconstruction, although he invoked these in his evolutionary model of the social economy (Boulding, 1981). Romer's new growth model is a neoclassical model without the assumptions of marginal rate of substitution and diminishing return, both representing scarcity of resources in the face of human well-being. But it can be readily inferred that a multiplicative form of the capital and labour knowledge-augmenting growth model must necessarily imply marginal rate of substitution between these variables. Substitution is a concept contrary to that of pervasive complementarities as was pointed out in the works of Myrdal and Kaldor (Toner, 1999c). ${ }^{4}$

The evolutionary learning model of endogenous complementarities via circular causation relations in this paper shares with, but yet differs from the genre of models in the Austrian vintage, specifically Schumpeter's model of development with creative destruction. The major difference is on the issue of continuity of technological enhancement in the evolutionary model of circular causation in this paper. Opposed to this is Schumpeter's discontinuity property in the growth of spending (investment), and the need for monopoly to cover up the slack caused by such temporary slowdown. On this issue, Gaffard (2009) writes: "As shown with the model used by means of numerical simulations, the introduction of the new technology generates an initial fluctuation, which brings about temporary unemployment as well as a temporary fall in productivity. However, this fluctuation very soon dampens down and the economy converges to a new steady-state corresponding to the superior technology, with a higher level of productivity - which allows lower prices and higher real wages - and full employment." This problem of a temporary halt in economic expansion causing disequilibrium in the Schumpeterian perspective of economic growth and development is overcome in the MFSRE-model by the continuous simulation of well-being with circular causation relations by learning, which represents appropriate technological change.

In the end, the MFSRE-model is not a model of jumping the tides of growth and development in the 'wants' economy. Instead, it is a model of appropriate technology that enhances the dynamic changes and sustainability of dynamic basic needs regimes of development. Conformably, the nature of money as a value of spending ${ }^{5}$ in the real economy brings about the dynamic changes by appropriate technology 
and financial instruments that interlink the sectors. Such intersectoral dynamics present the sign of systemic learning, and also the epistemological content of the MFSRE worldview. Cooperation and coordination by way of sectoral and inter-variables complementary linkages, and by way of sectoral inter-flow of resources replace the competitive and dismal cumulative causation model of the Austrian genre, especially that given by Myrdal and Schumpeter.

In the MFSRE worldview old and failing industries are not replaced. They are integrated into new industries by innovation and development. Nascent industry protection is carried on in the MFSRE model of evolutionary learning for interactively integrating followed by innovation. This feature is found in the Schumpeterian model but with a caution. Schumpeter writes: "There is certainly no point in trying to conserve obsolescent industries indefinitely; but there is a point in trying to avoid their coming down with a crash and in attempting to turn a rout, which may become a center of cumulative depressive effects, into orderly retreat." Thus there are profound similarity and some dissimilarity between the MFSRE and SchumpeterianAustrian development dynamics. Along with the continuous nature of increasingly enhancing the effect of technology and innovation on the growth of output the MFSRE-model by its formulation of the dynamic basic-needs approach to growth, development and wellbeing also establishes the money-spending complementarities. In such a case, the MFSRE becomes similar to the case that Schumpeter wrote about (Gaffard, 2009): "Active monetary and banking policies allow productivity gains associated with the introduction of a new and superior technology to be captured. As Schumpeter pointed out, money forces the economic system into new channels and allows a quasi-steady state to be re-established."

Yet in the case of MFSRE the complete interconnectivity between money and spending that brings about complementarities along moving and evolutionary equilibriums caused by the organic forms of the circular causation relations implies money as well as spending activities to flow along new channels of innovations and economic progress by creating total well-being. It is therefore, possible that the evolutionary perspectives of MFSRE and Schumpeterian model can converge in the dynamic basic-needs regime of development. But this will not be possible in any 'wants' economy for reasons of the failure to adopt appropriate technology and innovation that establish continuity of the endogenous relationship between complementary variables. The basic-needs regime instead, can attain what Schumpeter 
envisioned, as Gafford (2009) points out: "Schumpeter addresses the question of the intensity and the speed of structural changes and pleads for gradualism."

\section{An Economy with Endogenous Induction of Technology as Knowledge in the Evolutionary Relationship between Money and Spending Regimes with non-inflationary Stable Growth Yielding Well-being}

In the MFSRE-model the effectiveness of technological change as knowledge-flows acting over the growth of capital accumulation continuously in spending, and the growth of efficient units of labour by HRD, requires the micro-foundation of relationship between monetary and spending expansion. We have dwelled on this topic in this paper thus far. Weare now to investigate the financial consequences of such relations on the money-spending complementary effect on economic expansion.

Our arguments in this paper showed that when monetary and spending regimes become complementary then only the expansion of the real economy generates productive value. The financial sector now becomes a bridge-to carry money efficiently, subject to the level of knowledge available in the economic system-into spending. Now with the perfect money-spending complementarities realized with appropriate financial resource mobilizing instruments for the sole benefit of real sector growth and the variables in this sector that matter, the rate of interest ' $r$ ' and the cost of capital ' $c$ ' will run down to zero. In other words, there is no price of financial capital like the rate of interest for valuation of financial flows. Only prices in the real economy matter in yielding the value of the financial flows by the profitability of the goods.

The result then is the perfect working of the equation of exchange of the Fisher-type in the light of circular causation as shown in expressions (1)-(8) written down as, $M(\mu, \rho)^{*} \mathrm{~V}=\mathrm{P}^{*} \mathrm{y}(\mu, \rho)$, where $\mu$ is the yield rate. We differentiate in respect of $\mathrm{P}$ assuming that $\mathrm{V}=$ constant to start with. The result yields the following simplification:

$$
\mathrm{d} \log (\mathrm{M}) / \mathrm{dp}=\mathrm{d} \log \mathrm{P} / \mathrm{dp}+\mathrm{d} \log \mathrm{y} / \mathrm{dp}
$$

That is, $g(M) \cdot d M / d p=g(p)+g(y) \cdot d y / d p$

The $g($.$) symbols denote growth rates of the specified variables.$ 
By holding the target of price stability we obtain,

$$
\mathrm{g}(\mathrm{p}) \sim 0 \text {, yielding } \mathrm{g}(\mathrm{M}) \cdot \mathrm{dM} / \mathrm{dp} \sim \mathrm{g}(\mathrm{y}) \cdot \mathrm{dy} / \mathrm{dp}
$$

That is, $d M / d p \sim d y / d p ;$ or $M=a+b . y$, meaning that the value of $a$ quantity of money equals the value of real output, subject to the evolutionary learning capacity available.

Next by extension we write $M(\mu, \rho)=y(\mu, \rho)$

$\mathrm{M}$ and $\mathrm{y}$ are positive functions of $(\mu, \rho)$.

By a further extension we write in reference to the well-being concept of expressions (1)-(8),

$$
M(f, y, P, E, \mu, \rho)=a+b . y(M, f, P, E, \mu, \rho)
$$

Each of the bracketed variables has a positive relationship with $M$ and $y$ in the context of complementarities and well-being with the target of price stability within a given range as can be accommodated by the evolutionary learning in the variables. This is true either as a positivistic fact or a normatively reconstructed case of simulation as explained earlier.

Next we look at the specific form,

$$
M(f, y, P, E, \mu, r, c, \rho)=a+b . y(M, f, P, E, \mu, r, c, \rho),
$$

where ' $r$ ' is the real rate of interest; ' $c$ ' is the cost of capital.

Clearly, ' $r$ ' and ' $c$ ' have negative relationships with each of the other variables. Therefore, these rates cannot be acceptable in sustaining the effect of technological change on increasing non-inflationary growth and development with well-being. Therefore, a financial system is necessary and has arisen, and that replaces the ' $r$ '- and ' $c$ '- based financial instruments by the ' $\mu$ '-based ones. The positive complementarities between variables representing the sectors of the MFSRE model explain the efficacy of the ' $\mu$ '-based financial instruments.

The economic example of such a case is Islamic economy with its financial and banking system (Choudhury, 2011a). The Islamic system works on the basis of the epistemology of unity of knowledge, which stands for organically-learned complementarities between the good things of life as these are represented by the variables of the sectors 
in the integrated MFSRE-model. Well-being is the natural corollary of the complementarities between Money (M), Finance (F), Spending or spending (S), and Real Economy (RE) as the interacting, integrating, and evolutionary sectors by virtue of their inherent learning processes.

The Islamic financial instruments promoting resource mobilization (Mankiw \& Rashwan, 2012) as spending into the real economy are principally the primary ones, such as, profit-sharing (mudarabah), equity participation and joint venture (musharakah), and markup asset pricing or hire-purchase pricing (murabaha). Besides these, there are the secondary financing instruments such as, rental (ijara), deferred asset valuation (bay' muajjal), contractual payment in manufactures (wadia), Islamic bonds in mega-projects (sukuk), and charitable donations (qard e-hasana). The integrated nature of MFSRE-model advocates a mixed portfolio with diversification between all the financing instruments mentioned here and more (Mufeedh Choudhury, op cit).

The yields in the above-mentioned kinds of asset pricing, even during the financial crisis, have remained approximately at 7 per cent annually in Islamic banks world-wide, and projects have flourished at the micro-level (Mankiw \& Rashwan, 2012). Demand for the Islamic portfolio has remained resilient. This is proved by the Malaysian Islamic capital market with its 20 per cent of the capitalization in the stock market; by the highest number of depositors of all banks in Islamic Bank Bangladesh, which earned the reputation of being the best Islamic bank world-wide by the Global Finance Forum.

In the Arab Gulf and MENA region the demand for Islamic financial portfolio can be seen by the following evidence (Mega Middle East Advisors, 2006): The number of rich households and their wealth in the GCC region (CAGR for liquidity was 7\% between 2003 and 2006; number of wealthy households increased by 6 per cent CAGR between 2003 and 2006) increased even as GDP and privatization picked up (CAGR of nominal GDP was 19 per cent between 2002 and 2006). Within the wealth formation there was a 40 per cent share of the capital market that preferred Islamic over conventional funds. There was preference for high returns over stable return among this class of investors. Additionally, 20 per cent of the market share in the GCC region was made up of investors that preferred pure Islamic funds. These investors preferred Shari'ah-compliant investments over conventional ones, no matter what the performance of the Islamic funds was. The rest of the 40 per cent share of the capital market was of investors in the GCC region preferring conventional funds. 
The composition of the Islamic capital market was made up of portfolios of equity (Sukuk, CAGR 232 per cent between 2002 and 2006; private equities CAGR 36 per cent between 2000 and 2006), real estate (CAGR 36 per cent between 2002 and 2006), and Islamic insurance (Takaful, CAGR 13 per cent between 2002 and 2005). In general, Islamic funds increased by CAGR 22 per cent between 2000 and 2006, but with a focus on medium to small enterprises.

The Islamic investment picture for the MENA region is similar. Forty per cent of MENA Islamic investments were in real estate. This was followed by 17 per cent in financial services; 14 per cent in travel and tourism; and 29 per cent in private equities. In all, Islamic funds in MENA experienced a CAGR of 130 per cent between 2002 and 2006.

Our implications of money-finance-spending-real economy circular causation relations are reflected in the choice of Islamic diversified portfolio contrary to the independence of the financial sector as a competing one with the real economy. Thus our results concerning the nature of the MFSRE-model are supported by the evidence of the GCC and MENA regions.

\section{Estimation and Simulation of Circular Causation Relations in Money and Real Economy Relations, the Case of Malaysia}

The following results point out how the estimation and simulation of well-being subject to circular causation relations are carried out and the results obtained there from in order to analyse the inter-variables complementary issue for attaining well-being.

\section{Estimated equations ${ }^{6}$}

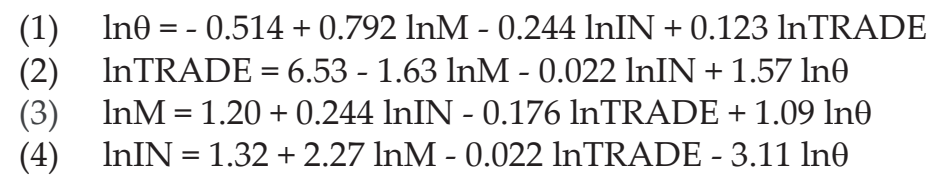

Simulated equations (using the SDA numerical choices for selected coefficients)

(2') $\ln T R A D E=6.53-1.417 \cdot \ln M-0.022 \ln I N+1.57 \ln \theta$

(3') $\ln M=1.20+0.103 \ln I N-0.103 \ln T R A D E+1.09 \ln \theta$

(4') $\ln I N=1.32+1.672 \ln M-0.022 \ln T R A D E-3.11 \ln \theta$

(5) $\ln \theta=-0.514+0.792 \ln \mathrm{M}-0.244 \operatorname{lnIN}+0.123 \ln \mathrm{TRADE}$ 
IJMS 20 (1), 1-39 (2013)

Tables 1 and 2 give the estimated and simulated values, respectively, for all the variables over the time-period 1990-2008 for Malaysia. These values are charted in Figures 2, 3, 4 and 5.

Table 1

Estimated Values of the Natural Logarithm Variables and the Well-being Index $\theta$ Theta)

\begin{tabular}{ccccc}
\hline Year & $\operatorname{lnM}$ & $\ln I N$ & $\ln$ Trade & $\ln$ Theta \\
\hline 1990 & 3.028729 & 2.281141 & 4.474355 & 1.89087 \\
1991 & 3.016001 & 2.271952 & 4.493234 & 1.83810 \\
1992 & 2.934276 & 2.435738 & 4.436823 & 1.77571 \\
1993 & 3.04094 & 2.249392 & 4.480648 & 1.90399 \\
1994 & 3.034887 & 1.741766 & 4.756527 & 2.04736 \\
1995 & 2.937106 & 1.93596 & 4.695302 & 1.92750 \\
1996 & 2.952987 & 1.958982 & 4.698482 & 1.84772 \\
1997 & 2.769532 & 2.219091 & 4.626825 & 1.73527 \\
1998 & 2.657149 & 2.162338 & 4.742497 & 1.57792 \\
1999 & 2.902974 & 1.17243 & 5.151269 & 2.01929 \\
2000 & 2.785608 & 1.304155 & 5.083616 & 2.10319 \\
2001 & 2.809719 & 1.332004 & 5.067209 & 2.08539 \\
2002 & 2.892835 & 1.137896 & 5.149293 & 2.12385 \\
2003 & 2.987651 & 0.967619 & 5.214237 & 2.15912 \\
2004 & 2.949029 & 0.951494 & 5.223702 & 2.18411 \\
2005 & 2.959712 & 0.895367 & 5.249401 & 2.19897 \\
2006 & 2.928511 & 1.111181 & 5.130819 & 2.16884 \\
2007 & 3.000422 & 1.10347 & 5.097477 & 2.22294 \\
2008 & 2.921725 & 1.169502 & 5.081687 & 2.21855 \\
\hline
\end{tabular}

Table 2

Simulated (Predictor) Values of the Natural Logarithm Variables and the Well-being Index $\theta$

\begin{tabular}{ccccl}
\hline Year & $\ln \mathrm{M}$ & $\ln I N$ & $\ln T$ rade & \multicolumn{1}{l}{$\ln$ Theta } \\
\hline 1990 & 3.033362 & 0.460517 & 5.122838 & 1.8785 \\
1991 & 3.008144 & 0.474554 & 5.133444 & 1.872984 \\
1992 & 2.915919 & 0.671824 & 5.065107 & 1.761356 \\
\hline
\end{tabular}


IJMS 20 (1), 1-39 (2013)

\begin{tabular}{lllll}
\hline Year & lnM & lnIN & lnTrade & lnTheta \\
\hline 1993 & 3.046929 & 0.420285 & 5.132153 & 1.896692 \\
1994 & 3.132733 & -0.076 & 5.403994 & 2.049692 \\
1995 & 3.007119 & 0.172046 & 5.323586 & 1.917336 \\
1996 & 2.993872 & 0.217396 & 5.318813 & 1.924687 \\
1997 & 2.803798 & 0.553654 & 5.220033 & 1.70711 \\
1998 & 2.683936 & 0.60593 & 5.29687 & 1.646178 \\
1999 & 3.082529 & -0.5183 & 5.753487 & 2.132689 \\
2000 & 3.008451 & -0.39361 & 5.68834 & 1.999273 \\
2001 & 3.019396 & -0.36925 & 5.673175 & 2.009555 \\
2002 & 3.10907 & -0.58386 & 5.762562 & 2.132842 \\
2003 & 3.204128 & -0.78043 & 5.83687 & 2.257472 \\
2004 & 3.182752 & -0.79333 & 5.845187 & 2.231982 \\
2005 & 3.199642 & -0.85268 & 5.872034 & 2.257299 \\
2006 & 3.14622 & -0.64327 & 5.755731 & 2.165343 \\
2007 & 3.214216 & -0.69688 & 5.738739 & 2.220077 \\
2008 & 3.149172 & -0.60986 & 5.715475 & 2.139696 \\
\hline
\end{tabular}

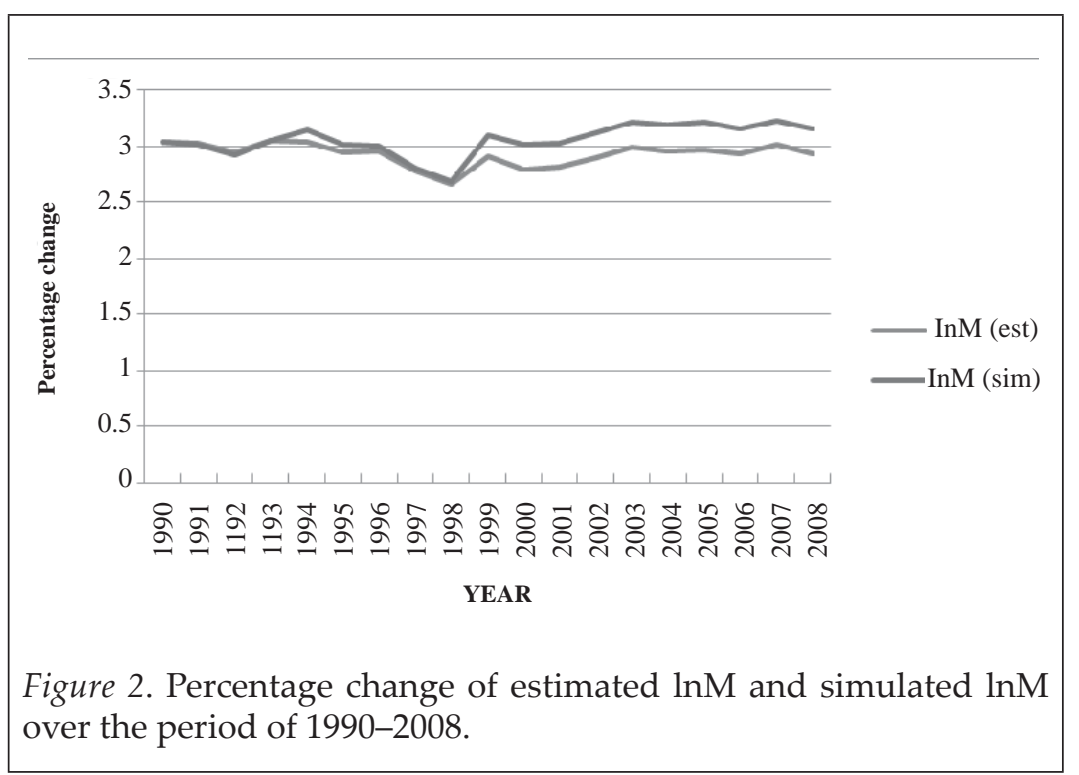


IJMS 20 (1), 1-39 (2013)
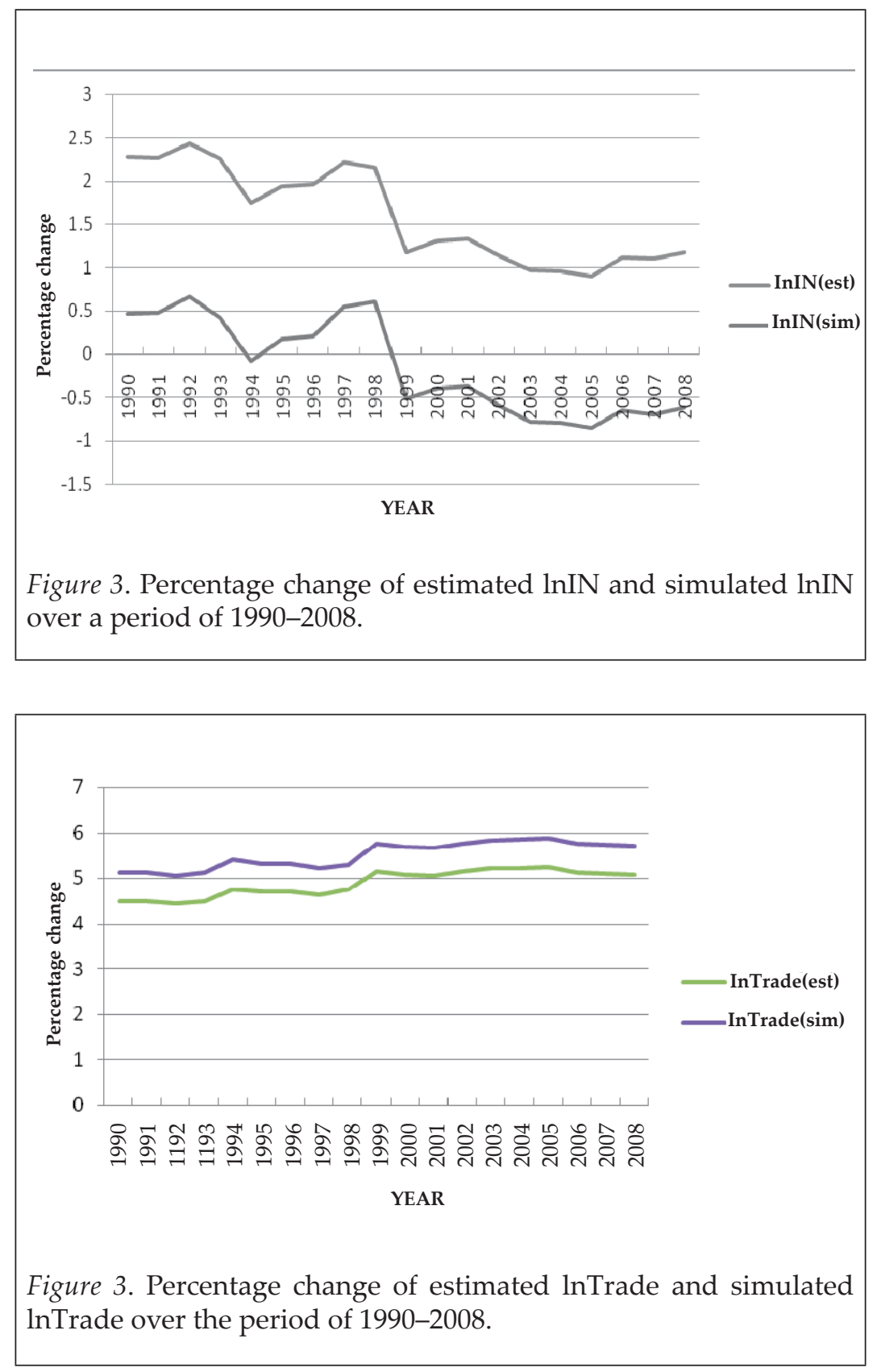
IJMS 20 (1), 1-39 (2013)

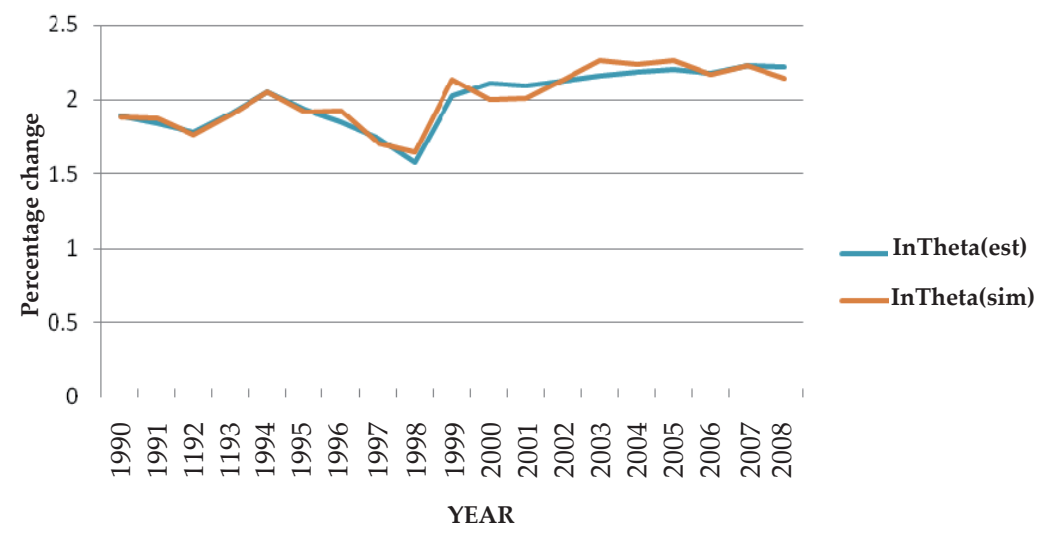

Figure 4. Percentage change of estimated lnTheta and simulated lnTheta over the period of 1990-2008.

\section{Regression Analysis}

Regression analysis: $\ln M^{*} 100, \ln I N \%, \ln T R A D E^{*} 100, \ln \theta$

1. Regression Analysis: $\ln M$ versus $\ln I N, \ln T R A D E, \ln \theta$

The regression equation is

$$
\ln \mathrm{M}=1.20+0.244 \ln \mathrm{IN}-0.176 \ln \mathrm{TRADE}+1.09 \ln \theta
$$

\begin{tabular}{lrccc}
\hline Predictor & Coef & SE Coef & $\mathrm{T}$ & $\mathrm{P}$ \\
\hline Constant & 1.2043 & 0.5362 & 2.25 & 0.040 \\
$\ln I N$ & 0.2444 & 0.0564 & 4.33 & 0.001 \\
$\ln$ TRADE & -0.1763 & 0.0715 & -2.46 & 0.026 \\
$\ln \theta$ & 1.0860 & 0.1129 & 9.62 & 0.000 \\
\hline
\end{tabular}

$S=0.0408542 \quad R-S q=88.1 \% \quad R-S q(\operatorname{adj})=85.8 \%$

Durbin-Watson statistic $=1.57629$

2. Regression Analysis: $\ln I N$ versus $\ln M, \ln T R A D E, \ln \theta$

The regression equation is

$$
\ln \mathrm{IN}=1.32+2.27 \ln \mathrm{M}-0.022 \ln \mathrm{TRADE}-3.11 \ln \theta
$$


IJMS 20 (1), 1-39 (2013)

\begin{tabular}{lcccc}
\hline Predictor & Coef & SE Coef & $\mathrm{T}$ & $\mathrm{P}$ \\
\hline Constant & 1.317 & 1.859 & 0.71 & 0.490 \\
$\ln \mathrm{M}$ & 2.272 & 0.525 & 4.33 & 0.001 \\
$\ln \mathrm{TRADE}$ & -0.022 & 0.259 & -0.08 & 0.935 \\
$\ln \theta$ & -3.106 & 0.454 & -6.84 & 0.000 \\
\hline
\end{tabular}

$\mathrm{S}=0.124582 \quad \mathrm{R}-\mathrm{Sq}=96.0 \% \quad \mathrm{R}-\mathrm{Sq}(\mathrm{adj})=95.1 \%$

Durbin-Watson statistic $=1.45823$

3. Regression Analysis: $\ln T R A D E$ versus $\ln M, \ln I N, \ln \theta$

The regression equation is

$$
\operatorname{lnTRADE}=6.53-1.63 \ln \mathrm{M}-0.022 \ln \mathrm{IN}+1.57 \ln \theta
$$

\begin{tabular}{lcccc}
\hline Predictor & Coef & SE & T & P \\
\hline Constant & 6.532 & 0.8467 & 7.71 & 0.000 \\
$\ln \mathrm{M}$ & -1.635 & 0.6632 & -2.46 & 0.026 \\
$\ln \mathrm{N} N$ & -0.022 & 0.2577 & -0.08 & 0.935 \\
$\ln \theta$ & 1.568 & 0.8266 & 1.90 & 0.077 \\
\hline
\end{tabular}

$\mathrm{S}=0.124388 \quad \mathrm{R}-\mathrm{Sq}=87.1 \% \quad \mathrm{R}-\mathrm{Sq}(\mathrm{adj})=84.5 \%$

Durbin-Watson statistic $=0.887537$

4. Regression Analysis: $\ln \theta$ versus $\ln M, \ln I N, \ln T R A D E$

The regression equation is,

$$
\ln \theta=-0.514+0.792 \ln \mathrm{M}-0.244 \operatorname{lnIN}+0.123 \operatorname{lnTRADE}
$$

\begin{tabular}{lcccc}
\hline Predictor & Coef & SE & T & P \\
\hline Constant & -0.5142 & 0.5125 & -1.00 & 0.332 \\
$\ln M$ & 0.7923 & 0.0824 & 9.62 & 0.000 \\
$\ln I N$ & -0.2437 & 0.0357 & 6.84 & 0.000 \\
$\ln q$ & 0.1234 & 0.0651 & 1.90 & 0.077 \\
\hline
\end{tabular}

$S=0.0348958 \quad R-S q=97.2 \% \quad R-S q(\operatorname{adj})=96.6 \%$

Durbin-Watson statistic $=1.87454$ 


\section{SDA results ${ }^{7}$}

Note that the ethical index remains almost unchanged in the estimated and the normative equations because of the correct signs of the variables related to $\ln \theta$. But predictor (simulated) values are different from the estimated values.
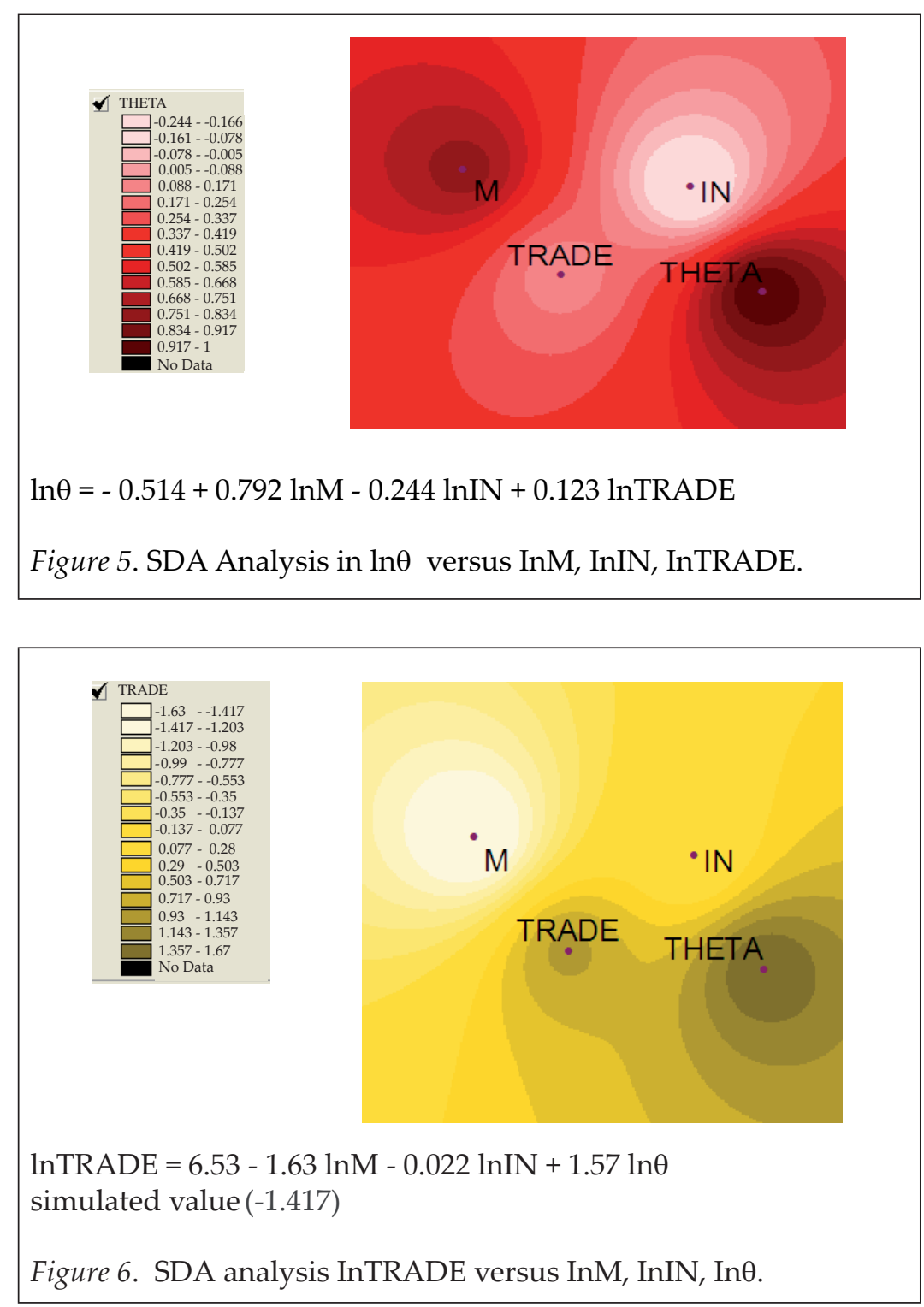
IJMS 20 (1), 1-39 (2013)
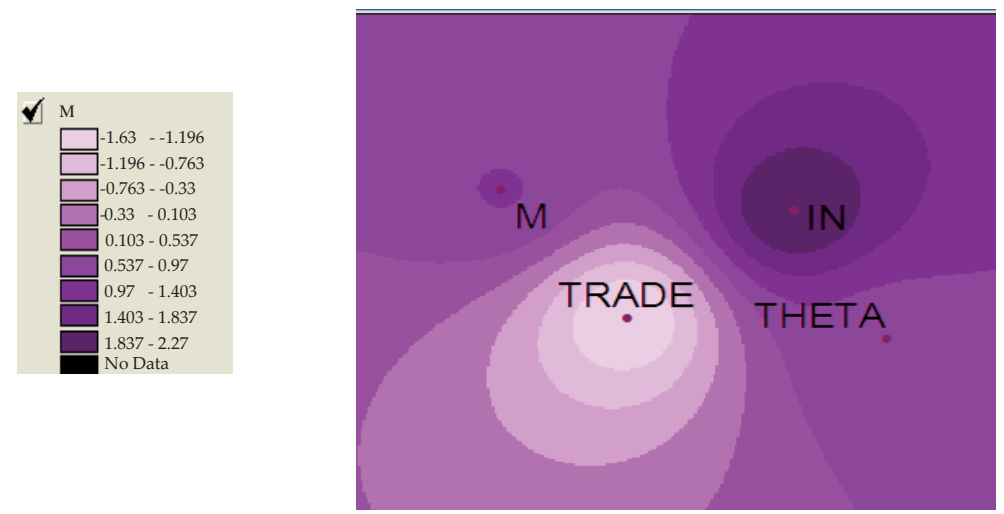

$\ln \mathrm{M}=1.20+0.244 \ln \mathrm{IN}-0.176 \ln \mathrm{TRADE}+1.09 \ln \theta$ simulated value $(0.103)(0.103)$

Figure 7. SDA Analysis InM versus ININ, InTRADE, $\operatorname{In} \theta$.

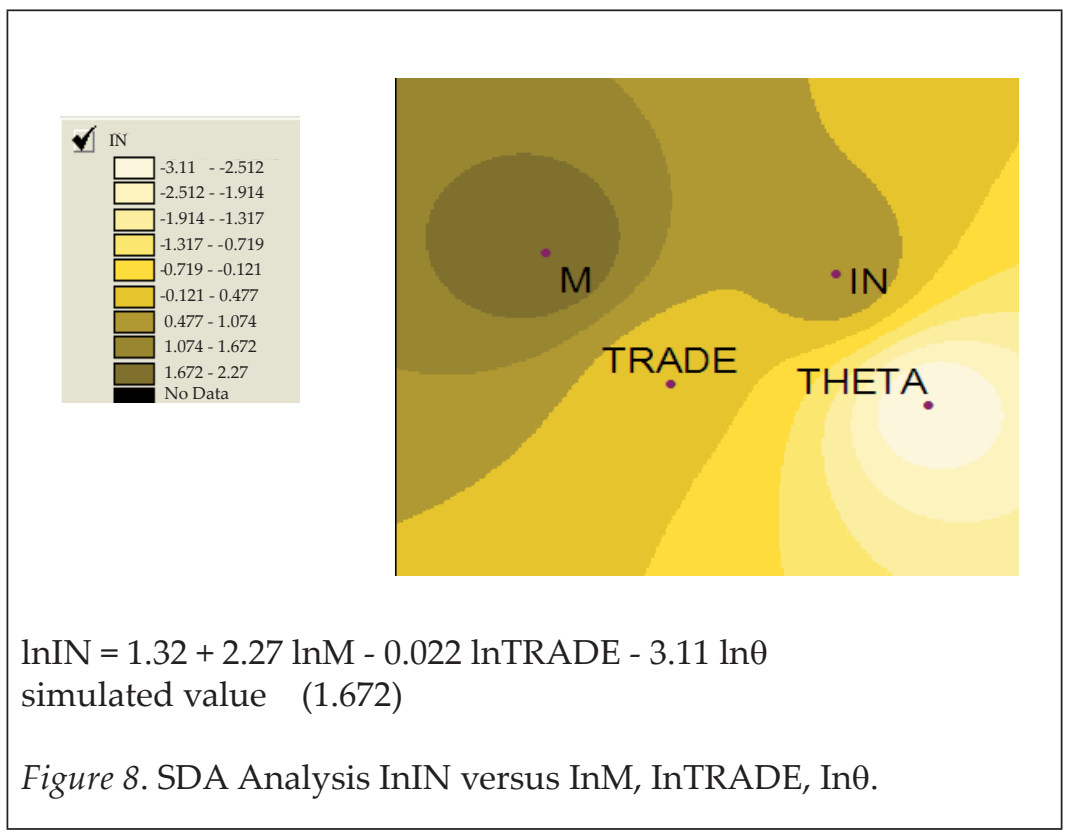




\section{Conclusion}

The principal contribution of this paper has been to extend the thinking on the macroeconomic stabilization by monetary and spending regimes and policies to the controversial area of complementarities between these two 'good' ways for macroeconomic coordination by means of implementing policies. The complementarities between monetary and spending regimes have raised controversies traditionally due to the post-Keynesian criticism of spending using Friedman's monetarism theory on price stability. Blaug wrote on this point (1993, p. 216): "The great debate between Keynesian and monetarists over the respective potency of spending and monetary policy had divided the economic profession, accumulating what is by now a simply enormous literature." Blaug continues (p. 221): “... monetarism never succeeded in clarifying the causal mechanism that produced its empirical results, sometimes even denying that these results required interpretation in the light of a supporting causal theory, and it failed to refute any but a crude travesty of the Keynesian theory it opposed. ... Keynesianism on the other hand, proved to be capable of absorbing monetarist ideas in a ore-sophisticated brand of macroeconomics that appears to be emerging from the fifteen-yearold melee."

Such opposing reflections on either side have led to the dismay in economic thought and in macroeconomic policy coordination at the level of industrial countries and its followership by developing countries. The emergence of a sustainable or at least a search for a universal theory of macroeconomic policy coordination, politicoeconomic institutionalism, and economic stabilization has failed.

But a consequence of an even more concerning nature is the deepening, missing and exogenous treatment of the topic of well-being. Thus, the macroeconomic divide has caused a methodological impossibility on several fronts. Firstly, the issue runs deep into the problem of demarcation between deductive and inductive reasoning in scientific thought that always remained intrinsic to occidental minds. It was championed by Popper and joined in by Samuelson (Boland, 1989).

In the classical age of scientific thought in the West the origins can be traced down to the methodological approach to reasoning laid down by Kant (1964, 1977), the deductive champion; and by Hume (1992), the inductive champion. The possibility and search, leave alone the discovery of at least a way toward a universal theory of macroeconomic 
coordination, has failed. To this failure also adds on those of welldefining the micro-foundation of macroeconomic methodology, the nature of relationship between money and spending, and their total effects on total well-being. Thereby, the understanding of endogenous ethics in economics, and the emergence of a new epistemology, that of unity of systemic knowledge in these directions, have not dawned. Such a grand failure has occurred despite the great minds of the scientific economic tapestry.

Economic stabilization gained simply by short-run policies and remedial instrumentation of economic disturbances lost between monetary and spending regimes by themselves is inadequate in addressing the ultimate goal of well-being. Contrarily, such a goal is deeply moral, ethical, and social in nature. Such forces are embedded in the endogenous nature of ethics in economic reasoning at the most rigorous level and depth of intellec (Sen, 1990).

We overcome such epistemological limitation of economic theory despite the works of the Austrian School of Economics (von Mises, 1960) to relegate the ultimate premise of economic reasoning to rationalism. The search and the possibility for a methodological theory of 'everything', and the quest for universality even by the most rigorous of argumentation have been left out in economic theory (Choudhury, 2011b). In this paper such an ultimate epistemology of socio-scientific reasoning has been addressed. This is to show the methodology towards unification of the deductive and inductive episteme and thus to organize socio-scientific reasoning upon the emergent episteme of moral and ethical endogeneity.

The ultimate premise of this new socio-scientific argumentation taken up in economics has been presented in this paper in terms of the episteme of unity of knowledge. This has been made to work through the micro-foundation of macroeconomic stabilization theme using the objective criterion of well-being defined by pervasive complementarities between the 'good' things of life. The most elemental one of such good things is the knowledge to gain unity of being and becoming. Monetary and spending regimes are thus studied by the principle of pervasive complementarities. The empirical examples given in this paper, point out that such an ultimate epistemology of 'everything' is possible.

For the last words, we borrow from Gaffard who eulogizes the great Schumpeterian legacy: "On the other hand, industrial policy must create incentives for firms to engage in co-operation, which is the 
key to the viability of such a complex process as innovation, which is characterized by interaction among multiple actors. This is not meant to eliminate the competitive character of the market, but to strengthen the co-ordinating role of competition."

In our paper we have fully replaced competition by systemic complementarities as the sure sign of the functional ontology of unity of knowledge and participatory dynamics, hence replacing competition by cooperation everywhere. The result was a generalized system and cybernetic approach as opposed to a general equilibrium approach to economic modelling (Skyttner, 2005). This paper has thus integrated ethics, evolutionary learning, and well-being along with the theme of complementarities between money and spending regimes with economic stabilization.

\section{End Notes}

1 Spending here means the sum-total, $\mathrm{Y}_{\mathrm{GDP}}=$ Consumption spending + investment + government expenditure in as much as any government expenditure ought to make the real sector grow by affecting positively consumption and investments in a growing and technologically-induced real economy.

2 In a simple time-dependent version of the quantity theory, MV = P.y; where $\mathrm{M}$ denotes quantity of money. $\mathrm{V}$ denotes the velocity of money supply. P denotes price level. y denotes real output. Over time in terms of growth rates denoted by $g(),. g(M)+g(V)=g(P)+g(y)$. In the simplifying case let $\mathrm{V}=$ constant, and assume the presence of real interest rate ' $r$ ', and fiscal spending ' $\mathrm{f}$ '. The above equation then assumes the form, $\mathrm{g}(\mathrm{M}(\mathrm{r}, \mathrm{y}))=$ $\mathrm{g}(\mathrm{P}(\mathrm{r}, \mathrm{y}, \mathrm{f}, \mathrm{M})+\mathrm{g}(\mathrm{y}(\mathrm{r}, \mathrm{M}, \mathrm{f}))$.

By time-derivatives we obtain the following inferences: $\mathrm{g}(\mathrm{M}(\mathrm{r}, \mathrm{y}))=(1 / \mathrm{M})^{*}\left[(\partial \mathrm{M} / \partial \mathrm{r})^{*}(\mathrm{dr} / \mathrm{dt})+(\partial \mathrm{M} / \partial \mathrm{y})^{*}(\mathrm{dy} / \mathrm{dt})\right]$. This expression has no definite sign by theory; for monetary demand may decline sufficiently by the r-effect in order to displace the monetary equilibrium to a declining trend with increasing ' $r$ '. Yet there can also be a positive effect of ' $r$ ' on $\mathrm{M}$ over time on the contrary. Likewise, depending upon the relative effects of various monetary components, increasing change in y over time can be linked to decreasing monetary effect if the effect of money in circulation is weaker than that of other interest-bearing monetary components.

In the same way there is no definite theoretical sign of $g(y(r, M, f))=$ $(1 / y)^{*}(\mathrm{dy} / \mathrm{dt})$. In this case, if the source of generating $\mathrm{y}$ is the productive one, then $\partial \mathrm{y} / \partial \mathrm{r}<0$ with $\mathrm{dr} / \mathrm{dt}>0$. Contrarily, if the growth of $\mathrm{y}$ depends more on the financial source of income generation, then $\partial \mathrm{y} / \partial \mathrm{r}<0$ with $\mathrm{dr} /$ $\mathrm{dt}>0$. Yet theoretically, $\partial \mathrm{y} / \partial \mathrm{M}>0 ; \mathrm{dM} / \mathrm{dt}>0$ together; $\partial \mathrm{y} / \partial \mathrm{f}>0$ and $\mathrm{df} / \mathrm{dt}$ $>0$ simultaneously. 
Hence in the end, the sign of $\mathrm{g}(\mathrm{P}(\mathrm{r}, \mathrm{y}, \mathrm{f}, \mathrm{M}))$ remains indeterminate. A degree of uncertainty in price variations along with variations in ' $r$ ' and $M$ relationship is introduced in the system of interrelations between the variables $(r, y, f, M)$. The interrelationship between $M$ and $f$ mechanisms remain uncertain. Besides, the result is an uncertainty due to the extensive variations in the term structure of a labyrinth of short-term interest rates. The effect is felt both on the aggregate demand curve and the IS curve of the expenditure sector; and on the aggregate supply curve and the LM curve by the kind of indeterminateness of the signs of the terms as mentioned above.

3 The following three equations on money $(\mathrm{m})$ and price $(\mathrm{p})$ movements in terms of output $\left(\mathrm{y}^{*}\right)$ and given interest rate with all variables in natural logarithmic form:

$\mathrm{m}_{\mathrm{t}}=\mathrm{p}_{\mathrm{t}}+\mathrm{y}_{\mathrm{t}^{\prime}} \mathrm{p}_{\mathrm{t}}=\mathrm{E}\left(\mathrm{p}_{\mathrm{t}-1}\right)+\gamma\left(\mathrm{y}-\mathrm{y}^{*}\right)$

with $\mathrm{y}^{*}$ being targeted $\mathrm{y} ; \mathrm{m}=\mathrm{m}^{*}+\varepsilon, \mathrm{m}^{*}$ being targeted $\mathrm{m}$ and $\varepsilon$ being normally distributed error term, are solved by the Rational Expectation method to yield the final result,

$\mathrm{y}=\mathrm{y}^{*}+(1 /(1+\gamma)), \mathrm{p}=\mathrm{m}^{*}-\mathrm{y}^{*}+(\gamma /(1+\gamma)) \varepsilon$.

Here $\left(\mathrm{m}^{*}-\mathrm{y}^{*}\right)$ is the anticipated part of adjustment of $\mathrm{m}$ to output as in M1 form of money or the transaction demand for money. The unanticipated part $(\gamma /(1+\gamma)) \varepsilon$ is unpredictable due to its probabilistic nature.

Thus, output and the quantity of money are related in an unpredictable nature. Consequently price and output stability is untenable. Such unpredictable quantity of money for real economic growth has proved to be problematic even for industrialized economies, such as the EU (Trichet, 2008).

4 Note that technological augmentation of labour (say $\gamma$, thus $\gamma \mathrm{L}$ ) must carry with it a similar augmentation of capital (say $\eta$, thus $\eta \mathrm{K}$ ) in the growth model: supply of nominal output,

$\mathrm{Y}(\mathrm{t})=\mathrm{F}(\gamma \mathrm{L}, \eta \mathrm{K})=\mathrm{A} \cdot(\gamma \mathrm{L})^{\alpha *}(\eta \mathrm{K})^{\beta}=\left[\mathrm{A}_{1}^{*} \gamma^{\alpha *} \eta^{\beta *}\right]^{*}\left[\mathrm{~A}_{2}{ }^{*} \mathrm{~L}^{\alpha *} \mathrm{~K}^{\beta}\right]=\mathrm{T}(\mathrm{t})^{*} \mathrm{~L}^{\alpha *} \mathrm{~K}^{\beta}$,

where $\mathrm{L}(\mathrm{t})$ denotes labour input; $\mathrm{K}(\mathrm{t})$ denotes capital input both at time $\mathrm{t}$. A now becomes the technological factor influencing output. In this form Romer's model is identical with Denison's model.

Consequently all the trappings of a marginal rate of substitution and marginal productivity of factor inputs are retained in this form of the technologically induced growth model. The endogenous effect of technological change on factor inputs and thereby on output growth thereby remains benign. 
It is not possible in Romer's concept of endogeneity to obtain the result $\mathrm{dL}(\mathrm{t}) / \mathrm{dK}(\mathrm{t})>0$ unless $\mathrm{L}(\mathrm{t})$ and $\mathrm{K}(\mathrm{t})$, and thereby $\mathrm{Y}(\mathrm{t})$ are induced by $\mathrm{T}(\mathrm{t})$. In other words, the time variable ' $t$ ' cannot act as the mobilizer of human resource as a technological effect. Human resource must be induced on the expansion path. Thus HR becomes exogenously induced in the growth model.

The concept of endogenous circular relations in this paper avoids the above kind of treatment that beleaguers the new growth theory. Instead, knowledge (technology) is induced in the variables. The above-mentioned problem of allocation of resources for attaining output maximization is replaced by the simulation model in which all variables remain complementary by the appropriate choice of technology.

In the end, any maximization objective is replaced by the well-being simulation. The well-being function is a monotonic technological function expressed in terms of the complementary variables and then revised by coefficient changes according to the demand and possibility of complementarities between the circular causation variables as shown in the system (1)-(8).

Toner (1999, p. 166) writes in regards to the externality property of technological change in new growth model, which once again gives a neoclassical semblance to the new (endogenous) growth model that wants to overcome the postulate of diminishing returns to scale: "This abandonment is achieved by invoking some externality that offsets any propensity to diminishing returns."

5 Quantity of Money = Total Spending by the equation of exchange with a subtle meaning: $\mathrm{MV}=\mathrm{Py}$. This implies that a portion of the total quantity of money denoted by MV equals the value of its expenditure in transactions on real things denoted by Py $=$ nominal value of output. However, if we further assume that the direction of money is into projects appearing in various interlinked sectors (say, $\mathrm{i}=1,2, \ldots, \mathrm{n}$ ) then, a micro-quantity of money $\left(\right.$ say $\left.\mathrm{M}_{\mathrm{i}}\right)$ flows fully to equate the spending $\left(\mathrm{P}_{\mathrm{i}} \mathrm{y}_{\mathrm{i}}\right)$ requirements of that project. Thereby, $\mathrm{M}_{\mathrm{i}}=\mathrm{P}_{\mathrm{i}} \mathrm{y}_{\mathrm{i}}$. In this case $\mathrm{V}_{\mathrm{i}}=1$ because a quantity of micro-money flows fully into specific projects.

Furthermore, because of the interlinked nature of the sectoral projects, total quantity of money arising from the micro-foundations is equal to

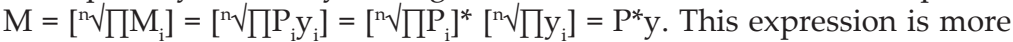
appropriate than the simple case of disjoint projects; therefore disjoint sectors that are spanned by such projects. In that case the total quantity of money circulating in given independently distributed projects would be the uninteresting case, $\mathrm{M}=\sum_{\mathrm{i}=1}{ }^{\mathrm{n}} \mathrm{M}_{\mathrm{i}}=\sum_{\mathrm{i}=1}{ }^{n} \mathrm{P}_{\mathrm{i}}^{*} \mathrm{y}_{\mathrm{i}}$.

The micro-foundations of the quantity theory of money expressed in terms of the disaggregate forms of the equation of exchange implies direct complementarities between money and spending with the real economy. 
In such a structure of economy there is no role for rates of interest and the cost of capital. These are replaced by real yields, rates of returns, profit rates and profit-sharing rates in the project-specific case.

6 This section is adapted from Noreha Halid, Mohammad Saleh Ahmed, Masudul Alam Choudhury, "Circular Causation Relations using Malaysian Data on Money and Real GDP, Chapter 10 of Choudhury, M.A. Islamic economics and finance: An epistemological inquiry, Bingley, UK: Emerald, 2012.

7 Spatial Domain Analysis (SDA) is a methodology within the Geographical Information System (GIS) that maps the interrelations between variables (hence entities), which can be represented in the real space. But when we treat the socioeconomic and abstract socio-scientific cases by means of SDA, we take the real space to be represented by measured variables. Such measurements can be actual data or ordinalized representations. By so representing the variables and abstract relations between variables visually by means of SDA technology, this is dealing with the modelling capability of the spatial interaction of the entities in their spatial domains.

GIS is a technology that facilitates the study of spatial cause-effect relations between $\{(\theta, x(\theta)$-domains and their entities. Thereby spatial domain analysis stores the requisite data into computer memory for doing SDA-work. The IIE-methodology, which is central in the learning model of unity of knowledge and is formalized by the significance of complementary relations in the circular causation relational system, can be simulated by SDA in connection with the econometric estimation methods. Consequently, IIE-model as a real-world system can be represented in a 'computer-world' according to SDA and GIS. The spatial analysis capability of GIS facilitates the manipulation of spatial information and helps generate various "what if" scenarios as necessary for evaluating decision-making processes on real-time basis. In this way, GIS becomes an appropriate tool to deal with the heart of the theme of Relational Epistemology, which is Interaction, Integration and Evolution (IIE).

\section{References}

Benanke, B., \& Mishkin, F. S. (2007). Inflation targeting: A new framework for monetary policy. In F. S. Mishkin, (Ed.), Monetary policy strategy (pp. 207-226). Cambridge, MA: The MIT Press.

Blaug, M. (1993). The methodology of economics. United Kingdom: Cambridge University Press.

Boland, L. A. (1989). On the methodology of economic model building. In Boland, L. A. (Ed.), The methodology of economic model building (pp. 39-63). London, Eng: Routledge. 
Boulding, K. E. (1971). Economics as a moral science. In F. R. Globe (Ed.), Boulding collected papers vol. 2. Boulder, CO: Association of University Press.

Boulding, K. E. (1981). Evolutionary economics. New York: Russell Sage.

Cantner, U., Luc Gaffard, J., \& Nesta, L. (2009). Schumpeterian perspectives on innovation, competition, and growth. New York: Springer.

Choudhury, M. A. (2011a). Islamic economics and finance: An epistemological inquiry. Bingley, UK: Emerald.

Choudhury, M. A. (2011b). A critique of economic theory and modeling: A meta-epistemological general-system model of Islamic economics. Social Epistemology, 25(4), 423-446.

Friedman, M. (1960). A program for monetary stability. New York: Fordham University Press.

Friedman, M. (1989). Quantity theory of money. In M. Friedman (Ed.), New palgrave: Money (pp. 1-40). London: MacMilan Press.

Gafford, J. (2009). Innovation, competition, and growth: Schumpeterian ideas within a Hicksian framework. In U. Cantner., J. Luc Gaffard., \& L. Nesta (Eds.), Schumpeterian perspectives on innovation, competition, and growth (pp. 7-24). New York: Springer.

Hume, D. (1992). Of the understanding. In his Treatise of human nature. Buffalo, N. Y: Prometheus Books.

Kaldor, N. (1975). What is wrong with economic theory? Quarterly Journal of Economics, LXXXIX(3), 347-357.

Kant, I. (1964; 1977). Groundwork of the metaphysics of morals. In H. J. Paton (Trans.), New York: Harper \& Row Publishers. See also Kant, I. (1664). Critique of pure reason. In C. J. Friedrich (Trans.), The philosophy of Kant. New York: The Modern Library.

Kirzner, I. (1997). Entrepreneurial discovery and the competitive market process: An Austrian approach. Journal of Economic Literature, $X X X V(1), 60-85$.

Lucas, Jr. R. E. (1975). An equilibrium model of the business cycle. Journal of of Political Economy, 83, 1113-1144.

Maturana, H. R., \& Varela, F. J. (1987). The tree of knowledge. London, Eng: New Science Library.

Mega Middle East Global Advisors. (2006). The Islamic funds and investments report 2006, UAE.

Minford, P., \& Peel, D. (1983). Rational expectations and the new macroeconomics. Oxford, Eng: Martin Robertson.

Mishkin, F. S. (2007a). What should Central Banks do? Monetary policy strategy. Cambridge, MA: The MIT Press.

Mishkin, F. S. (2007b). The transmission mechanism and the role of asset prices in monetary policy. Monetary policy strategy. Cambridge, MA: The MIT Press. 
Choudhury, Mufeedh. U. A. (2009). Money, finance, and the real economy in Islamic banking and finance: Perspectives from the Maqasid asShari'ah (Unpublished doctoral dissertation). Department of Economics, University of Stirling, UK.

Mankiw, G., \& Rashwan, M. H. (2012). Islamic finance. In their Principles of economics Middle East edition (pp. 575-592). Hampshire, UK: Cengage Learning.

Myrdal, G. (1957). An unexplained general traits of social reality. In his Rich lands and poor, the road to world prosperity. New York: Harper \& Row.

Myrdal, G. (1958). The logical crux of all science. In P. Streeten, (Ed.), Value in social theory, a election of essays on methodology by gunnar Myrdal (pp. 231-236). New York: Harper \& Brothers Publishers. Myrdal, G. (1958). The principle of cumulation. In P. Streeten (Ed.), Value in social theory, a selection of essays on methodology by Gunnar Myrdal (pp. 198-205). New York: Harper \& Brothers Publishers.

Romer, P. M. (1986). Increasing returns and long-run growth. Journal of Political Economy, 94, 1002-1037.

Sen, A. (1990). On ethics and economics. Oxford, Eng: Basil Blackwell.

Shakun, M. F. (1988). Evolutionary systems design, policy making under complexity and group decision support systems. Oakland, CA: Holden-Day.

Skyttner, L. (2005). General systems theory. Singapore: World Scientific Publishing.

Toner, P. (1999a). The marriage of young and keynes. In N. Kaldor (Ed.), Main currents in cumulative causation, the dynamics of growth and development (Chapter 6,). Houndmills, Hampshire: Macmillan Press.

Toner, P. (1999b). Gunnar Myrdal (1898-1987). Circular and cumulative causation as the methodology of the social sciences. In Main currents in cumulative causation, the dynamics of growth and development (Chapter 5,). Houndmills, Hampshire: Macmillan Press.

Toner, P. (1999c). Conclusion. In Main currents in cumulative causation, the dynamics of growth and development. (Chapter 7,). Houndmills, Hampshire: Macmillan Press.

Trichet, J-C. (2008, 17 January). The creation of economic and corporate wealth in a dynamic economy - Contribution to the panel. Speech delivered at Banque de France and the Conference Board, Frankfurt, Germany. 
Von Bertalanffy, L. (1974). Perspectives on general system theory. New York: George Braziller.

Von Mises, L. (1976). The ultimate foundation of economic science. Kansas City, Kansas: Sheed Andrews \& McMeel.

Von Mises, L. (1960). Epistemological problems of economics. Princeton, NJ: Princeton University Press.

Yeager, L. B. (1997). The fluttering veil, essays on monetary disequilibrium. Indianapolis, IN: The Liberty Press. 
